\title{
ENVOLVENDO ESTUDANTES DE DIREITO EM UMA EQUIPE MULTIDISCIPLINAR: ENSINO, PESQUISA, EXTENSÃO E RESPONSABILIDADE SOCIAL*
}

\section{INVOLVING LAW STUDENTS IN A MULTIDISCIPLINARY TEAM: EDUCATION, RESEARCH, EXTENSION AND SOCIAL RESPONSIBILITY}

\author{
Fabiola de Sampaio Rodrigues Grazinoli Garrido** \\ Rodrigo Grazinoli Garrido ${ }^{* * *}$
}

\begin{abstract}
Resumo: Trabalhos desenvolvidos em equipes multidisciplinares devem ser rotina para os futuros egressos do curso de direito. O objetivo desse artigo é discutir algumas estratégias e planos de trabalho utilizados no Programa de Educação Tutorial Conexões de Saberes que envolve estudantes do curso de direito da Universidade Federal Rural do Rio de Janeiro no campus de Três Rios, interior do Rio de Janeiro. Nessa perspectiva, o engajamento dos estudantes em projetos do tem contribuído como um campo experimental para o desenvolvimento das habilidades necessárias aos bacharéis em direito, bem como para a percepção do papel social do futuro profissional. Desde 2014, a equipe desenvolve projetos que discutem a função da universidade junto à comunidade, abordando sobretudo questões relacionadas a grupos vulneráveis e a aspectos agroambientais.
\end{abstract}

Palavras-chave: aprendizagem significativa; formação integradora; projetos na graduação.

\begin{abstract}
Work performed in multidisciplinary teams should be routine for future graduates of the law courses. The aim of this paper is to discuss some strategies and work plans used in the Connections of Knowledge Tutorial Program that involves law students of the Federal Rural University of Rio de Janeiro on the campus of Três Rios, in the interior of Rio de Janeiro. In this perspective, students' engagement in projects has contributed as an experimental field for the development of the skills required by law graduates, as well as for the perception of the social role of the professional future. Since 2014, the team has developed projects that discuss the role of the university in the community, addressing issues related to vulnerable groups and agro-environmental aspects.
\end{abstract}

Key words: meaningful learning; integrative training; graduation.

\footnotetext{
* Trabalho realizado com financiamento do FNDE no âmbito do Programa de Educação Tutorial Conexão de Saberes por uma Formação Integradora e Cidadã no Campus de Três Rios da UFRRJ.

** Professora Associada - UFRRJ/ITR/DCMA. Tutora do PET Conexões de Saberes do Instituto Três Rios/UFRRJ. Programa de Pós-graduação em Práticas em Desenvolvimento Sustentável - UFRRJ. Email: fabiola_srg@yahoo.com.br

*** Jovem Cientista, FAPERJ. Perito Criminal - Diretor do IPPGF/PCERJ. Professor Adjunto PPGD/UCP. Professor Adjunto - FND/UFRJ. E-mail: grazinoli.garrido@gmail.com
} 


\section{INTRODUÇÃO}

A interdisciplinaridade é discutida e experimentada tanto na vivência do papel social das profissões, quanto nas técnicas suficientes para se estimular a aprendizagem dentro da realidade do ensino em universidades (THIESEN, 2008). Esta forma de ensino-aprendizagem torna-se essencial, principalmente nos cursos de direito, nos quais, a partir da Resolução CNE de 2004, as Diretrizes Curriculares Nacionais (DCN) passaram a demandar profissionais reflexivos e críticos. Assim, certamente este profissional deve ser capaz de se relacionar com equipes de formações distintas e com pessoas com desejos diversos.

Além disso, quando um profissional do direito precisa, por exemplo, compreender as provas técnicas em um processo ou quando tenta compor um conflito, as habilidades, conhecimento e competência vão muito além daquelas construídas ou demandadas nas componentes curriculares que compõem os eixos de formação fundamental e profissional da graduação. Requer a concepção de um curso cada vez mais aberto a dialogar com outras carreiras.

Assim, o Programa de Educação Tutorial (PET) pode contribuir sobremaneira para a formação dos bacharéis em direito. Este programa foi instituído pela Lei 11.180/2005 e regulamentado pelas portarias n. ${ }^{\circ} 3.385 / 2005,{ }^{\circ} .^{\circ} 1.632 / 2006$, n. $^{\circ}$ 1.046/2007 e n. ${ }^{\circ}$ 976/2010, atualizada pela Portaria $n^{\circ} 343 / 2013$, orientando-se pela indissociabilidade entre ensino, pesquisa e extensão.

Frente às normativas e metas do programa, há que se considerar que a restrição a aulas expositivas limita o desenvolvimento de conteúdos em grupos interdisciplinares. Por outro lado, os trabalhos dentro do programa permitem a combinação de diferentes modalidades de projetos - pesquisa, ensino e extensão, aplicando diferentes metodologias ativas de ensino-aprendizagem como trabalho em equipe e a problematização da realidade. Dessa forma, é possível revisitar conteúdos formais em espaços de aprendizagem informais e não formais, valorizando as interações sociais e permitindo que ele perceba seu papel social de forma autônoma a partir da oportunidade de visitas guiadas, observação de populações vulneráveis e contato com estudantes de outros níveis.

Este artigo propõe apresentar, a partir da observação participante, as atividades realizadas no contexto do Programa de Educação Tutorial Conexões de 
Envolvendo estudantes de direito em uma equipe multidisciplinar: ensino, pesquisa, extensão e responsabilidade social

Saberes por uma Formação Integradora e Cidadã no Campus de Três Rios da UFRRJ, entre os anos de 2014 e 2016. Pretende-se exemplificar como, já na universidade, futuros profissionais de diversos cursos, entre eles os de direito, podem trabalhar juntos em temas comum, muitos de interesse agroambiental, cada qual contribuindo com suas competências e habilidades obtidos na formação específica, e como essa atuação em diversos contextos sociais pode contribuir para a própria formação dos estudantes e para a percepção do papel social da futura atuação profissional.

\section{AS ATIVIDADES DO PET}

Inicialmente, o PET tem a preocupação de oferecer a base acadêmica necessária para que o estudante tenha autonomia em produzir e trabalhar com a informação que se originará dos projetos desenvolvidos pelo programa. Assim, o aluno iniciando no PET, tem experimentado atividades que permitem o desenvolvimento de habilidades necessárias à execução dos projetos, fomentando a capacidade e a aptidão para a aprendizagem autônoma e dinâmica (BRASIL, 2004).

$\mathrm{O}$ incentivo à pesquisa e à extensão, como necessário prolongamento da atividade de ensino e como instrumento para a iniciação científica, demanda da Resolução $n^{\circ} 9$ do Conselho Nacional de Educação (BRASIL, 2004). Na verdade, reafirmação da finalidade da Educação Superior, como descrito na LDB-96 (BRASIL, 1996), é o próprio mister do PET (BRASIL, 2013).

Assim, muitas vezes é proposto ao estudante fazer pesquisas de campo, entrevistas para obter dados que serão interpretados nos projetos. Para tanto, a observação das declarações e diretrizes sobre pesquisas com seres humanos que constam na Resolução 196/96 do Conselho Nacional de Saúde, bem como na Resolução $\mathrm{n}^{\mathrm{o}} 510$, de 07 de abril de 2016, busca suscitar uma postura ética com os sujeitos pesquisados e contribuir com a sólida formação humanística demandada para o curso (BRASIL, 2004). Para tanto, foram ofertados minicursos de bioética na pesquisa com seres humanos.

Outro momento importante na trajetória da educação científica desses estudantes é o exercício dos hábitos de leitura e da escrita. Nesse sentido, os alunos são amparados pela visão aperfeiçoada dos especialistas que se propõem a orientá-los na escrita e no processamento do conhecimento previamente publicado. O estímulo ao uso 
das ferramentas de comunicação apresenta a necessidade de aprimoramento para a comunicação de ideias, sendo certo que a leitura, compreensão e elaboração de textos, bem como a pesquisa e utilização da legislação, da jurisprudência, da doutrina são esperadas na formação destes futuros profissionais (BRASIL, 2004). Dessa forma, também foram oferecidos minicursos aos integrantes do programa, bem como à comunidade, que habilitaram os participantes para o uso avançado de softwares com ferramentas de edição de textos e planilhas de cálculos.

Independentemente de se tratar de um curso de direito, a internacionalização, a análise de provas técnicas, jurisprudências, direito internacional e fundamentos filosóficos e sociológicos exigem o conhecimento de línguas. Muitos estudantes que fazem iniciação científica dentro do programa também anseiam pela pósgraduação e pela mobilidade internacional. Isso aponta o papel fundamental na orientação vocacional e no apoio aos programas de pós-graduação. Assim, foi inevitável oferecer cursos de inglês básico e de interpretação de textos para o apoio à compreensão de publicações técnicas e para a admissão à pós-graduação.

Os cursos eram ministrados por voluntários e os participantes eram vinculados a um projeto de coleta de mantimentos não perecíveis destinados a instituições que abrigavam crianças, ou idosos, ou pacientes em situação de vulnerabilidade socioeconômica. Tal contrapartida em relação aos cursos foi uma decisão do grupo. A expectativa sobre o apoio de instituições com itens de higiene pessoal e alimentos não perecíveis foi estabelecer um olhar diferenciado em direção às obras sociais que estão estabelecidas na cidade.

Essa forma de agir é, por si só, um dos objetivos do PET ao “[...] estimular o espírito crítico, bem como a atuação profissional pautada pela cidadania e pela função social da educação superior" (BRASIL, 2010).

De posse das bases da escrita acadêmica e interpretação de dados, a produção de textos e a organização de encontros técnico-científicos passou a ser um objetivo natural para os alunos. A participação dos membros foi apoiada pelo programa e pela Pró-reitoria de Graduação, à qual se vinculava mais intimamente o programa na Universidade Federal Rural do Rio de Janeiro (UFRRJ). A análise dos relatórios individuais e do rendimento escolar revelaram uma superação das expectativas em relação à qualificação dos estudantes. Isso corroborou uma das metas, que se propõe ao 
Envolvendo estudantes de direito em uma equipe multidisciplinar: ensino, pesquisa, extensão e responsabilidade social

“[...] planejamento das atividades dos grupos em conformidade com o projeto pedagógico institucional e das formações em nível de graduação” (BRASIL, 2010)

\subsection{As perspectivas dentro da carreira}

A despeito de Mariosa e Dos Santos (2015), em uma pesquisa restrita com 100 alunos concluintes do curso de direito do Sul de Minas Geral, Brasil, terem observado um percentual significativo interessado em continuar sua formação em cursos de extensão, especialização e mestrado após a formatura, é certo que ainda perdura na formação dos estudantes de direito uma perspectiva muito restrita para a carreira logo após formados. Em geral, os recém bacharéis buscam ser aprovados na prova da Ordem dos Advogados do Brasil (OAB) e passar em um concurso público (PAGANI, 2011). Essa autora considera ainda que, de forma recorrente, há anos, são pouquíssimos os que se propõem a buscar formação para uma carreira acadêmica, ligada à pesquisa e à docência. Dessa forma, muitos docentes do curso de direito, atuam no ensino como um trabalho temporário, um trabalho extra e seus alunos reproduzem essa tendência.

Assim, o mercado de trabalho fora da Universidade tem oferecido mais oportunidade para os alunos do direito do que para nos aqueles dos outros cursos envolvidos no programa - Administração, Economia e Gestão Ambiental -, o que adia alguns planos relacionados à carreira acadêmica.

Contrário a tudo isso, o PET acaba por propor essa imersão na vida acadêmica, na pesquisa, na extensão e no ensino. Isto parece estar de acordo com o Projeto Pedagógico do Curso, aprovado pelo Conselho de Ensino, Pesquisa e Extensão (CEPE) da UFRRJ em 2013. No documento percebe-se um anseio pela formação do graduando que deverá superar a formação dogmática (UFRRJ, 2013).

\footnotetext{
O empenho em promover nos alunos uma atitude reflexiva e crítica sobre o pensar e fazer jurídico e seu papel na promoção de uma sociedade mais justa através da perspectiva interdisciplinar realiza-se por meio de grupos e projetos de pesquisa, projetos e programas de extensão, atividades complementares e programa de educação tutorial (PET/MEC) envolvendo todos os cursos do Instituto Três Rios e a editoração da primeira revista eletrônica do Curso de Direito da UFRRJ. É de se notar o investimento no aperfeiçoamento profissional e aprofundamento intelectual do corpo docente e o enfoque interdisciplinar de seus estudos, confirmando a proposta de construção de um curso de Direito reflexivo e articulado às questões e dinâmicas sociais (UFRRJ, 2013).
}

A formação integral oferecida pela educação tutorial também proporcionou a imersão em áreas especializadas, tais como a Medicina Legal. A despeito da 
importância cada vez maior dada à prova técnica e do advento de novos direitos (MACHADO et al, 2015), como o Biodireito, com seus questionamentos, sobretudo relacionados ao início da vida e ao momento derradeiro da morte, essa disciplina, bem como outras relacionadas à Ciência Forense não foram mencionadas nas DCN de 2004 (BRASIL, 2004).

No caso do curso no ITR/UFRRJ, como ocorre na maior parte do Brasil, mesmo com demanda crescente por parte dos alunos, a componente curricular, Medicina Legal, encontra-se no rol da optativas, não tem sido oferecida desde o início do curso, pois carece de professor. Dessa forma, o PET organizou um curso de extensão em medicina legal que acontece anualmente. Embora os estudantes de direito fossem maioria do público participante, os demais cursos também apresentavam ouvintes que prestariam concurso público para o cargo de perito criminal e investigador em Minas Gerais. Foi uma oportunidade interessante para que todos pudessem pensar situações comuns aos currículos dos cursos de graduação do campus, desenvolvendo outro objetivo do PET e das DCNs em desenvolver atividades acadêmicas de qualidade e interdisciplinares, relacionadas ao mercado de trabalho (BRASIL, 2004; 2010).

Outra proposta que contribuiu significativamente para a construção do egresso de direito foram as resenhas apresentadas no jornal do grupo - Jornal Conectar. As resenhas de livros acompanhavam o eixo temático assumido para o ano corrente. A ideia das resenhas surgiu livre em relação à obra. Cada membro do grupo apresentava trimestralmente a resenha de uma obra lida. Com o tempo, tem a pretensão de aumentar o discurso e de despertar novos projetos. Isso significa que inicialmente os estudantes escolheram as obras para a resenha. Em seguida, o eixo temático foi apresentado e as pessoas deveriam escolher livros que apresentassem de alguma forma o tema proposto. Em um momento, por exemplo, foi a bioética.

Todas as propostas pareceram fortalecer o grupo. Foi a forma mais simples para se alcançar o interesse dos estudantes frente às tecnologias e ofertas que são mais rápidas do que o espaço acadêmico. Envolver, cativar e despertar tem sido bons caminhos, necessários para se fazer pesquisa, quando eles pensam que fazem extensão. Não é o único caminho, mas foi importante para tocar na motivação pessoal dos envolvidos em projetos acadêmicos. Com o passar do tempo, a necessidade inicial de apenas cumprir atividades abonadas como atividades acadêmicas complementares nos 
Envolvendo estudantes de direito em uma equipe multidisciplinar: ensino, pesquisa, extensão e responsabilidade social

projetos pedagógicos de curso transformou-se em vontade, esperança de construir novos laços com a sociedade.

\subsection{Resultados dos projetos de extensão}

É certo que a extensão universitária proporciona aos graduandos em direito “[...]uma maior sensibilidade e solidariedade com os problemas do "outro", do diferente, do marginalizado, do excluído, levando [...] um maior contato com o mundo externo, com a sociedade e com a vida humana "(COLAÇO, 2006, p.238).

O trabalho inicial da equipe foi mergulhar na elaboração de uma cartilha com instruções para a formação de cooperativas. O trabalho em grupo e a problematização da realidade possibilitou que os participantes se reunissem em torno do resgate histórico de cooperativas; da legislação; dos tipos de cooperativas; da tributação; da sustentabilidade e responsabilidade social. Dessa forma, os alunos do direito precisaram aprofundar seus estudos no que se relaciona às relações trabalhistas do ponto de vista sociológico e legal, pois a teoria cooperativista, a teoria sociológica do trabalho e o próprio direito do trabalho, desenvolveram-se inter-relacionadas (ALCÂNTARA., 2014).

Inicialmente, conduziu-se um estudo dentro das áreas e os materiais produzidos foram apresentados à equipe. A linguagem foi adaptada para o melhor entendimento por pessoas que não tivessem ensino médio completo. À época, emergia na região a organização de produtores de alimentos orgânicos que revendiam sua produção em feiras e através de redes sociais. O programa PAIS - Produção Agroecológica Integrada e Sustentável - foi levado ao município conurbado de Paraíba do Sul, cuja produção abastecera a microrregião de Três Rios.

Esse trabalho finalizado foi distribuído ao público em 2014. Foi o marco na união dos estudantes em torno da elaboração de um material instrucional. Eles puderam observar que o conhecimento encerrado em uma linguagem mais simples colabora para a economia local. O mérito do projeto residiu no posicionamento do estudante como um sujeito ativo (MOREIRA e MASINI, 2001). Eles processaram as informações e pensaram na apresentação do material, na linguagem, nos elementos gráficos. Além disso, interagiram com a comunidade local, contribuindo sobremaneira para a formação dos futuros bacharéis em direito, pois como percebido por De Toledo (2015), esses 
estudantes não são estimulados a pensar, a exercitar o raciocínio, mas apenas a reproduzir as ideias dos doutrinadores.

Outro ponto que cabe ser destacado foi o fato de se propor uma inversão nos papeis dos participantes do projeto. No lugar de receberem as informações sobre cooperativismo, os estudantes se viram responsáveis pela formação dos participantes, responsabilizando-se pelas informações ali apresentadas e, por vez, temendo tal posição em virtude da responsabilidade assumida sobre as vidas que confiaram em seus ensinamentos. Perceberam, assim, o esforço realizado pelos docentes em busca de garantir a atenção dos estudantes e passar-lhes informação clara e importante para a formação, além do papel político do ato de ensinar. Eles são jovens em contato com um meio acadêmico do qual já se sabe o que esperar entre as inúmeras aulas expositivas. $\mathrm{O}$ desconhecido, o processamento de informações, a contribuição para a sociedade edifica, responsabiliza e amadurece.

Outra proposta de extensão resultou em um livro. O Memorial da Ditadura Militar nasceu da sensibilização do grupo acerca do apoio de populares ao retorno do regime militar. Os trabalhos da Comissão Nacional da Verdade, a ascensão de militantes ao primeiro governo de Luiz Inácio Lula da Silva (2002 - 2006) que engrossavam as frentes de luta armada nas décadas de 1960 e 1970 e a esquerda na América Latina foram alguns dos fatos históricos que reacenderam os debates em torno do regime militar (SALES, 2015). Após os 50 anos do regime ditatorial no Brasil, o programa apresentou uma mesa redonda e uma exposição de manifestações culturais e artísticas no campus. A concepção do evento, passando pela seleção dos temas a serem abordados foi uma construção que envolveu os estudantes. Em 2017, o projeto foi aprovado para receber fomento da FAPERJ (Fundação de Amparo à Pesquisa do Estado do Rio de Janeiro), através do Edital de Editoração APQ3.

O livro tem como autores os palestrantes da mesa redonda, colaboradores especialistas e alguns dos estudantes à época, os quais atualmente estão vinculados a programas de pós-graduação. Através desse projeto, a proposta veio à tona com um significado especial. A pesquisa que foi feita para se compor o memorial selou a união dos participantes na obra que será publicada.

\subsection{O contato com escolares}


Envolvendo estudantes de direito em uma equipe multidisciplinar: ensino, pesquisa, extensão e responsabilidade social

A convivência dos graduandos do Programa de Educação Tutorial revelou bastante as angústias em relação a suas atuações enquanto estudantes. Muitos perceberam os impactos das carências que traziam da Educação Básica. Esse fato ora repercutiu em desistências, ora foi um dos componentes que agravou a retenção na graduação, mas acima de tudo foi estímulo para a percepção de que poderiam contribuir para mudar essa realidade. Assim, os bacharelandos passaram a se dedicar a auxiliar alunos do Ensino Médio a reduzirem tais deficiências, através de projetos com as escolas.

Uma das ações foi a organização do preparatório para estudantes que prestarão o ENEM (Exame Nacional do Ensino Médio). Semanalmente, os estudantes vinculados ao programa oferecem aulas aos estudantes de Ensino Médio selecionados entre os escolares da rede pública da cidade de Três Rios. Uma das estudantes de Direito ensina produção textual. O que pode ser observado em projetos como esse é que, normalmente, os voluntários haviam sido beneficiados por algum projeto desse escopo anteriormente. Além do conteúdo programático, é oferecida orientação em relação aos cursos oferecidos no campus de Três Rios.

O projeto Encontros entre a Universidade e a Escola emerge do anseio pelo retorno da universidade como um espaço crítico e aberto à comunidade, especificamente, aos escolares. Na edição de 2015, as escolas trouxeram seus estudantes ao Instituto Três Rios e receberam informações coletivamente em um primeiro momento (Figuras 1). Em seguida, foram apresentados à vida universitária, às carreiras, ao movimento estudantil. A proposta foi deixar que o estudante se inscrevesse livremente no grupo de trabalho que o interessasse.
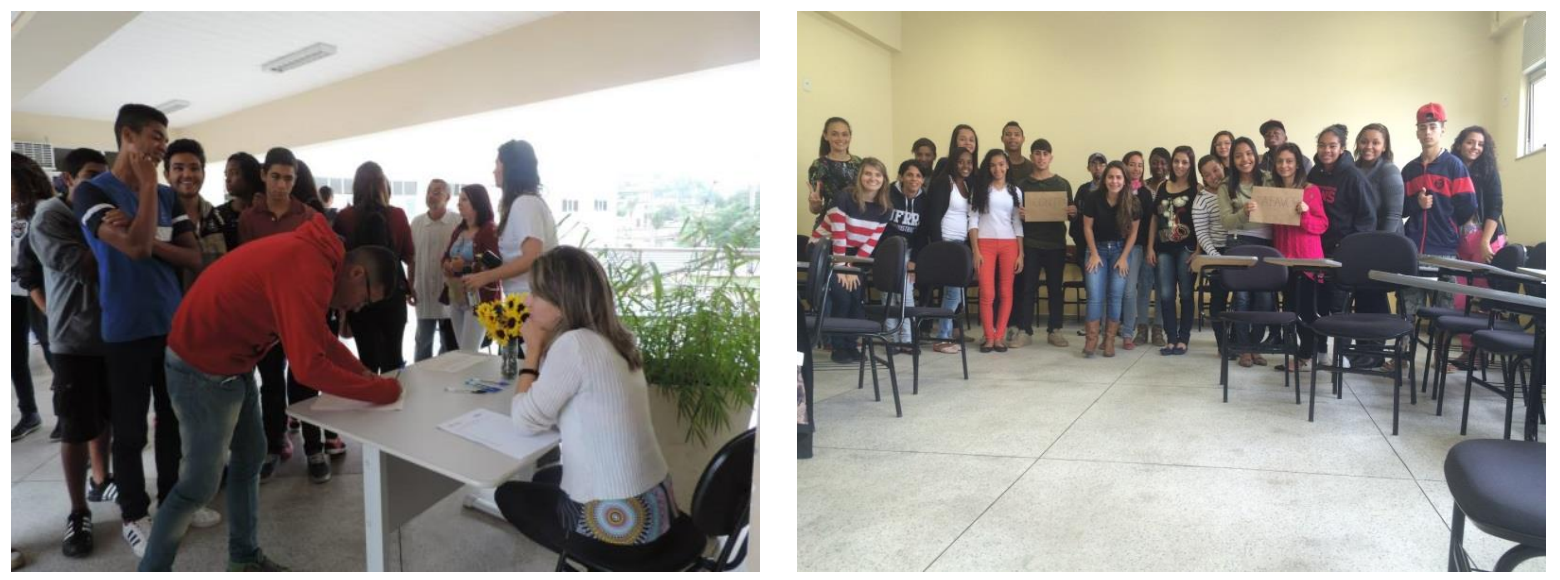

Figura 1 - Escolares inscrevendo-se nos grupos de trabalho, à esquerda, e, à direita, o Grupo de Trabalho sobre redução da maioridade penal. Fotos: Camila Lidizzia. 
Os temas dos grupos de trabalho abordaram bioética, direitos civis, distribuição de renda, economia social e sustentabilidade. No ano anterior, os temas haviam sido: redução da maioridade penal, programa Bolsa Família, crimes ambientais, bancos de perfis genéticos com fins de persecução penal, corrupção na Petrobras. Cada subgrupo, sob a presidência de um de nossos membros, utilizou um método diferente, que foi da encenação à exibição de documentários curtos. Sempre em uma ação de mão dupla, onde a informação dada aos estudantes de Ensino Médio, contribuía diretamente para a formação dos graduandos, desenvolvendo-se mutuamente (VIGOSTKI, 1998).

A equipe foi responsável pela concepção da abordagem e análise dos dados colhidos. A análise das expressões dos escolares, de forma escrita ou através dos depoimentos foi feita sob a ótica do estudante de graduação. O modelo da aprendizagem baseada em problemas oportunizou a participação dos escolares como sujeitos ativos (TAVARESs, 2004 e FERNANDES, FLORES e LIMA, 2012). Além disso, possibilitou que os estudantes de graduação se posicionassem como futuros profissionais, contextualizados em relação às suas inserções institucional, política, geográfica e social (BRASIL, 2004).

\subsection{O recurso aos espaços não formais e informais de aprendizagem}

A ampliação do conceito de educação é proposta por Gohn (2001 e 2004) na aplicação do conceito comunidade educativa. Ela envolveria o entorno da unidade escolar, incluindo-se os movimentos sociais, sindicatos, associações religiosas, Organizações Não-governamentais (ONGs), organizações de empresários e a população do entorno propriamente dita. Nessa interface emergem situações que configuram a educação não formal. Assim, na formação integral dos estudantes deve-se buscar ir ao encontro desses espaços.

$\mathrm{Na}$ verdade, a formação do bacharel em direito no Brasil, tinha em suas primeiras escolas, em 1827, em São Paulo e Olinda, a pretensão de servir à estrutura administrativa do Império, e manteve uma visão bastante tecnicista, até meados de 1970 (SILVA, 2000). De forma ainda mais radical, De Toledo (2015) considera que este direcionamento tecnicista acompanhou o egresso dos cursos de direito até a Resolução n 9 de 2004 do CNE. Quando, a inserção de disciplinas como Antropologia, Psicologia, História e Ciência Política no currículo buscaram contribuir com uma formação acadêmica voltada às práticas cidadãs e humanistas (De TOLEDO, 2015). Assim, dos 
Envolvendo estudantes de direito em uma equipe multidisciplinar: ensino, pesquisa, extensão e responsabilidade social

quase dois séculos de ensino de direito no Brasil, somente nos últimos anos, e mais especificamente após 2004, que passamos a buscar mais concretamente que o ensino de direito traga ao aluno a consciência de seu verdadeiro papel social (BRASIL, 2004).

Esse conceito pode ser aplicado na execução de projetos que envolvem as comunidades no entorno da universidade. Ao se depararem com as demandas da população, que necessita de instruções para conseguirem desfrutar da dignidade de uma vida civil, foi possível sensibilizá-los para novas propostas.

Ao ampliar a visão sobre o funcionamento e as estruturas da sociedade, é possível encontrar novos paradigmas e propostas para a garantia da cidadania. Para um estudante do direito, por exemplo, uma visita ao Jardim Botânico do Rio de Janeiro se supera ao apresentar discussões em torno da tutela jurídica dos recursos da biodiversidade e dos conhecimentos tradicionais, ou dos direitos à moradia e de propriedade aos quais fazem jus as comunidades tradicionais instaladas anteriormente à criação de unidades de conservação. Tratou-se dos jardins botânicos como centros de pesquisa, portadores do patrimônio genético e cultural.

Tendo em vista as ações propostas, é comum que o grupo seja procurado por pessoas da comunidade para o enfrentamento e discussão de questões relacionadas à carência de políticas públicas eficazes e para as ausências do poder público. Os componentes já se propuseram a participar de seminários para discutir a destinação final de resíduos sólidos, como proposto pelo Rotary. Em outro momento, os membros participaram de propostas destinadas à melhoria da qualidade da Educação Básica. Tudo pode ser uma interface com a sociedade e uma fonte viva para o processo de aprendizagem.

Tendo em vista a amplitude da violência doméstica no Brasil, o PET propôs o I Colóquio de Prevenção da Violência contra a Mulher. Na perspectiva de discutir vivenciar especialmente questões sobre a violência contra a mulher, ainda em 2016, o programa reuniu mulheres, policiais militares da divisão Guardiões da Vida e o Coletivo Feminino da Rural de Três Rios para estabelecer um diálogo sobre a Lei 11.340 de 2006, a Lei Maria da Penha.

O colóquio contou com apresentações dos convidados, relatos de casos atendidos pelos participantes, bem como abriu um momento de debate com a comunidade. Nesse momento, além das nuances legais, discutiram-se o cumprimento das medidas protetivas, os sucessos e fracassos das instituições pela garantia do direito 
de existir e de se exercer a cidadania. Através desses momentos, foi especialmente possível se concretizar a aprendizagem e o caminho sociológico por trás da lei e as barreiras que ainda precisam ser transpostas, mesmo depois de dez anos de legislação específica, para a efetivação das propostas positivadas na Lei 11.340 pois, de acordo com De Campos (2017, p.10) lógica da centralidade da mulher vem sendo subvertida pela lógica do sistema de justiça penal tradicional.

\section{CONSIDERAÇÕES FINAIS}

Os projetos foram espaços importantes para a discussão interdisciplinar de economia, gestão ambiental e ciências jurídicas, sempre associando teoria e prática. No período entre 2014 e 2017, os membros do programa experimentaram muitas atividades e necessidade de união do grupo em torno de temas que demandavam discussão entre os diferentes cursos. A maturidade em lidar com o método científico foi um ganho ao longo do plano de atividades.

Outro destaque foi a preocupação com novas práticas pedagógicas para se reduzir a retenção em componentes curriculares historicamente mal vistos pelos estudantes. Novos ingressantes no PET, inclusive, foram beneficiados pelas sessões de tutoria e pelos materiais didáticos criados no programa.

O trabalho em grupo em projetos multidisciplinares foi importante para imbuir os membros da equipe de responsabilidade em relação à aplicação dos conhecimentos e competências da carreira. Desde a pesquisa bibliográfica, à discussão metodológica, sempre há um campo para que os bacharelandos percebam as habilidades que podem transformar e intervir na realidade social. Essa perspectiva foi destacada na análise dos documentos nacionais e institucionais.

A atuação em diversos contextos sociais, em especial junto aos mais vulneráveis, trouxe sentido à aprendizagem impregnada de cidadania. Assim, os projetos que colocaram em discussão e demandaram ações relacionadas aos direitos fundamentais e populações negligenciadas, gestão de resíduos, melhoria da qualidade do ensino em escolas públicas, direitos trabalhistas dentro de cooperativas de produtores de alimentos orgânicos e o papel da mulher no mercado de trabalho foram ao encontro dos objetivos descritos na legislação federal para o Programa de Educação Tutorial e nas resoluções do Conselho Nacional de Educação para os bacharelados em direito. 
Envolvendo estudantes de direito em uma equipe multidisciplinar: ensino, pesquisa, extensão e responsabilidade social

Todos os ex-petianos que se candidataram a vagas no mestrado apresentaram pontuações levadas em suas entrevistas, mostrando a maturidade científica e cidadã dos egressos. Foram aprovados em primeiro lugar no mestrado em Tecnologia Ambiental da UFF, em Economia na UNICAMP e UFF e na UFM. A equipe que compunha o PET nesse período também ficou motivada com a premiação de um dos trabalhos, publicações de resultados e participações em feiras, exposições e encontros científicos. Além disso, o grupo ficou reconhecido por sua capacidade de organização, produção escrita e pela participação política. A discussão em torno da violência contra grupos minoritários, crimes de ódio e apatridia também marcaram essa etapa do programa.

Em um vídeo com relatos de egressos do grupo PET, no qual destacaram pontos importantes da participação no programa, uma recém graduada do curso de direito apontou o programa de educação tutorial como um espaço para o desenvolvimento da carreira acadêmica, de laços com a comunidade local e do trabalho multidisciplinar.

De forma geral, ficou claro que as interações com diferentes atores e em diversas situações, como proposto pelo PET, contribuiu muito para o desenvolvimento dos futuros bacharéis em direito do ITR-UFRRJ, mostrando seu papel social, pois como futuros profissionais estarão atuando com pessoas, seus anseios e angústias, padrões morais éticos e morais, nos conflitos e mediações, nas misérias e riquezas (COLAÇO, 2006, p.237). Por fim, em uma visão Vygotskyana, as interações sociais favoreceram os bacharelandos na própria aprendizagem das habilidades do curso.

Todavia, o melhor resultado referente ao programa são de difícil quantificação, uma vez que foram maiores as transformações nas vidas daqueles que receberam os projetos e na carreira de nossos egressos.

\section{REFERÊNCIAS}

ALCANTARA, F.H.C. O Cooperativismo segundo o Direito e a Sociologia do Trabalho. Organização Social, Salvador, v. 21, n. 68, p. 937-956, mar. 2014

BRASIL. Lei no 9.394, de 20 de dezembro de 1996. Estabelece as diretrizes e bases da educação nacional. Disponível em: <http://www.planalto.gov.br/ccivil_03/leis/L9394.htm>. Acesso em 25 out 2017. 
BRASIL. CONSELHO NACIONAL DE EDUCAÇÃO. CÂMARA DE EDUCAÇÃO SUPERIOR. Resolução CNE/CES $\mathbf{N}^{\circ}$ 9, de 29 de setembro de 2004. Institui as Diretrizes Curriculares Nacionais do Curso de Graduação em Direito e dá outras providências. Disponível em <http://portal.mec.gov.br/cne/arquivos/pdf/rces09_04.pdf>. Acesso em: 18 out 2017.

BRASIL. Lei $\mathbf{n}^{\mathbf{0}}$ 11.180, de 23 de setembro de 2005 - Institui o Projeto Escola de Fábrica, autoriza a concessão de bolsas de permanência a estudantes beneficiários do Programa Universidade para Todos - PROUNI, institui o Programa de Educação Tutorial - PET, altera a Lei no 5.537, de 21 de novembro de 1968, e a Consolidação das Leis do Trabalho - CLT, aprovada pelo Decreto-Lei no 5.452, de 1 o de maio de 1943, e dá outras providências. Disponível em: <http://www.planalto.gov.br/ccivil_03/_ato2004-2006/2005/lei/111180.htm>. Acesso em: 25 out 2017.

BRASIL. MINISTÉRIO DA EDUCAÇÃO. Portaria no 976, de 27 de julho de 2010 Atualizada pela Portaria n ${ }^{\circ} 343 / 2013$ - dispõe sobre o Programa de Educação Tutorial PET. Disponível em: <http://sigpet.mec.gov.br/docs/Portaria_976_2010.pdf>. Acesso em 18 out 2017.

BRASIL. MINISTÉRIO DA EDUCAÇÃO. Portaria no 343, de 24 de abril de 2013 Altera dispositivos da Portaria MEC n 976, de 27 de julho de 2010, que dispõe sobre o Programa de Educação Tutorial - PET. Disponível em: <http://sigpet.mec.gov.br/docs/Portaria_343_2013.pdf>. Acesso em 18 out 2017.

COLAÇO, T.L. Humanização do ensino do direito e extensão universitária. Revista Sequência, n. 52, p. 233-242, 2006.

CAMPOS, C.H. Lei Maria da Penha: necessidade um novo giro paradigmático. RBSP, v. 11, n. 1, p. 10-22. 2017.

TOLEDO, C.M.Q. O Ensino Jurídico no Brasil e o Estado Democrático de Direito. Análise crítica ao ensino do Direito Penal. Ed. Verbatim. 2015, 128p.

FERNANDES, S.F.; FLORES, M.A.; LIMA, R.M. Aprendizagem baseada em projetos interdisciplinares no ensino superior: implicações ao nível do trabalho docente. Fourth International Symposium on Project Approaches in Engineering Education (PAEE’2012), São Paulo, p. 227-236, 2012.

GOHN, M. da G. Educação não-formal e cultura política. 2. ed. São Paulo: Cortez, 2001

GOHN, M. da G. A educação não-formal e a relação escola-comunidade. ECCOS Rev. Cient., UNINOVE, v. 6, n. 2, p. 39-65, 2004

MACHADO, M. E. L.; NUNES, L. R. C.; LASSAROT, M. B. S.; Garrido, R.G.; GARRIDO, F. S. R. G. A extensão universitária enquanto espaço de formação em medicina legal para cursos de direito. Caderno da Extensão, v.único, p. 48-51, 2015. 
Envolvendo estudantes de direito em uma equipe multidisciplinar: ensino, pesquisa, extensão e responsabilidade social

MARIOSA, M.A.S. e Dos SANTOS, M. O mundo do trabalho para os concluintes de um curso de Direito. Revista Pedagogía Universitaria y Didactica del Derecho. $\mathrm{n}^{\circ} 2$, vol. 2, p. 76-94, 2015.

MOREIRA, M.A.; MASINI, E. Aprendizagem Significativa: a teoria de David Ausubel. 2 ed. São Paulo: Centauro. 2001.

OLIVEIRA, J. F.. A Formação dos Professores dos Cursos de Direito no Brasil: A PósGraduação Stricto Senso. Cadernos ANPAE, v. 1, p. 1-13, 2011.

SALES, J. R. Guerrilha e revolução: um balanço dos estudos e debates sobre a luta armada contra a ditadura militar no Brasil. TALLER (Segunda Época). Revista de Sociedad, Cultura y Política en América Latina Vol. 4, N 5, 2015.

SILVA, E.M.T. Ensino de direito no Brasil: perspectivas históricas gerais. Psicol. Esc. Educ, v. 4, n. 1, p. 307-312, 2000.

UFRRJ. Conselho de Ensino, Pesquisa e Extensão. Deliberação 57 de 13 de maio de 2013. Aprova a reestruturação do Projeto Pedagógico do Curso (PPC) de Bacharelado em Direito do Instituto Três Rios, campus Três Rios

TAVARES, R. Aprendizagem significativa. Revista Conceitos, v. 55, n. 10, 2004.

THIESEN, J da S. A interdisciplinaridade como um movimento articulador no processo ensino-aprendizagem. Revista Brasileira de Educação v. 13 n. 39 set./dez. 2008.

VYGOTSKY, L.S. A formação social da mente. São Paulo: Martins Fontes, 1989.

Artigo recebido em 04 de novembro de 2017 e aceito em 28 de fevereiro de 2018 